\title{
Rethinking the Urban Bike Map for the 21st Century
}

\section{Nate Wessel \\ University of Cincinnati \\ bike756@gmail.com}

Michael Widener

University of Toronto

michael.widener@utoronto.ca

\begin{abstract}
"Bike maps," commonly produced by city governments to encourage bicycling, tend to rely heavily on subjective recommendations aimed at an ideal "typical cyclist." Such a typical cyclist is increasingly illusory as people take up cycling for ever more diverse and practical purposes. In order to make bike maps useful for a general audience, we need to rethink some of the basic assumptions these maps have been making. The question should be: what do all cyclists want to know, and how can this information be quantified and depicted such that cyclists can use it to make informed decisions? With this question foremost in mind, we explain the development of a bike map for Cincinnati, Ohio that (almost) completely avoids unquantifiable judgments and, we hope, lights the way for future development of the bike map genre.
\end{abstract}

KEYWORDS: bicycle; bike map; Cincinnati; cycling; infrastructure; transportation

\section{INTRODUCTION}

FOR MORE THAN a hundred years, bike maps have been politely suggesting where recreational cyclists might like to ride their bikes. This simple approach is breaking down as urban Americans increasingly take up cycling for very diverse reasons. The racer, the commuter, the shopper, and the leisure rider, even as stereotypes, let alone as individuals, have totally different abilities, destinations and desires. City departments of transportation (DOTs), which aim to encourage cycling primarily as a replacement for car trips, should acknowledge that many trips will not be motivated by a desire for leisure but by a desire to actually go somewhere. These potential bike trips will have ends too numerous to plan for, and may go to and start from places not usually thought of as "bike-friendly." What is needed is not more simple recommendations for more types of cyclists and more destinations, but more general information that cyclists can put to use for their own contingent purposes. Since such informative (and unpresumptuous) maps seem rare, this paper addresses the gap by presenting a method for more objectively detailing a wide range of street conditions that any sort of bicyclist will likely be concerned with.

\section{BACKGROUND}

BIKE MAPS HAVE BEEN around for as long as bicycles have been popular; a brief history of the bicycle and of its maps will help to illuminate the present state of the genre.

In the 1880s, the bicycle was booming for the first time in the United States after the invention of the chain-driven "safety bicycle," the same basic model still used today. This bicycle was born into a world of mud and cobble streets, some even paved with wood (Smith 1972). Riding was often rough, and cyclists, led by bicycle manufacturers, organized to advocate for paved roads in their cities and states. They formed, among other groups, the League of American Wheelmen, which at one point boasted of more than 100,000 members (Smith 1972). These organizations made maps of cities both to actually help cyclists navigate and to pressure politicians to pave the city's streets. They often rated pavements on a scale from "good" to "bad," a well-worn technique for inflaming the egos responsible for such facilities (for a current, non-bicycle example, see the "Infrastructure Report Card" from the American Society of Civil Engineers [2015], with its "failing" bridges and "F" letter grades). The cyclists and their supporters got the 


\section{GUIDE MAP}

OF THE

\section{CITY OF DETROIT FOR BICYCLISTS,} Showing Pavements.

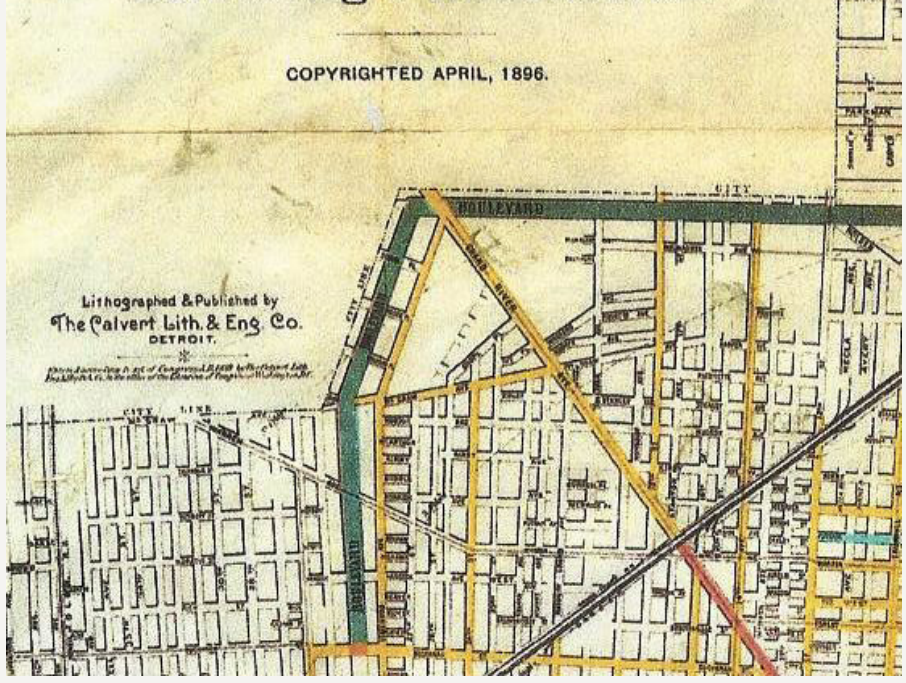

Figure 1. A bicycle map of Detroit from 1896 (Calvert Lith. And Eng. Co. 1896). paved roads eventually, but these simply enabled the next, motorized, product to come out of the bicycle factories: the car. The bicycle became, for several decades, largely a toy for children, at least in America (Longhurst 2015, ch. $5)$.

The 1970s saw a second "bike boom" in America (Longhurst 2015). Baby boomers, drawn by a desire for personal fitness, an affection for the environment, and the newly discovered cool of the European bike-racing scene (See for example the 1979 movie Breaking Away), bought racing-style road bikes by the thousands. These cyclists entered a world where smooth pavement was almost ubiquitous; the difficulty in riding was in dealing with their car-driving neighbors. The aim of these cyclists was largely recreational, and maps of the period, fewer in number than those of the earlier boom, seemed to mostly suggest more or less circuitous routes allowing people to ride as far as they pleased with relatively little disruption. The young boomers aged though, as we are all bound to do, and many of them eventually gave up riding.

Their children however, finding boredom in their suburbs and dusty bikes in their garages, began moving back to the cities with a new style of cycling. This period has brought enormous change in the way Americans use, perceive and accommodate bicycles (see Longhurst 2015) - a change only partly manifested as yet in contemporary bike maps.

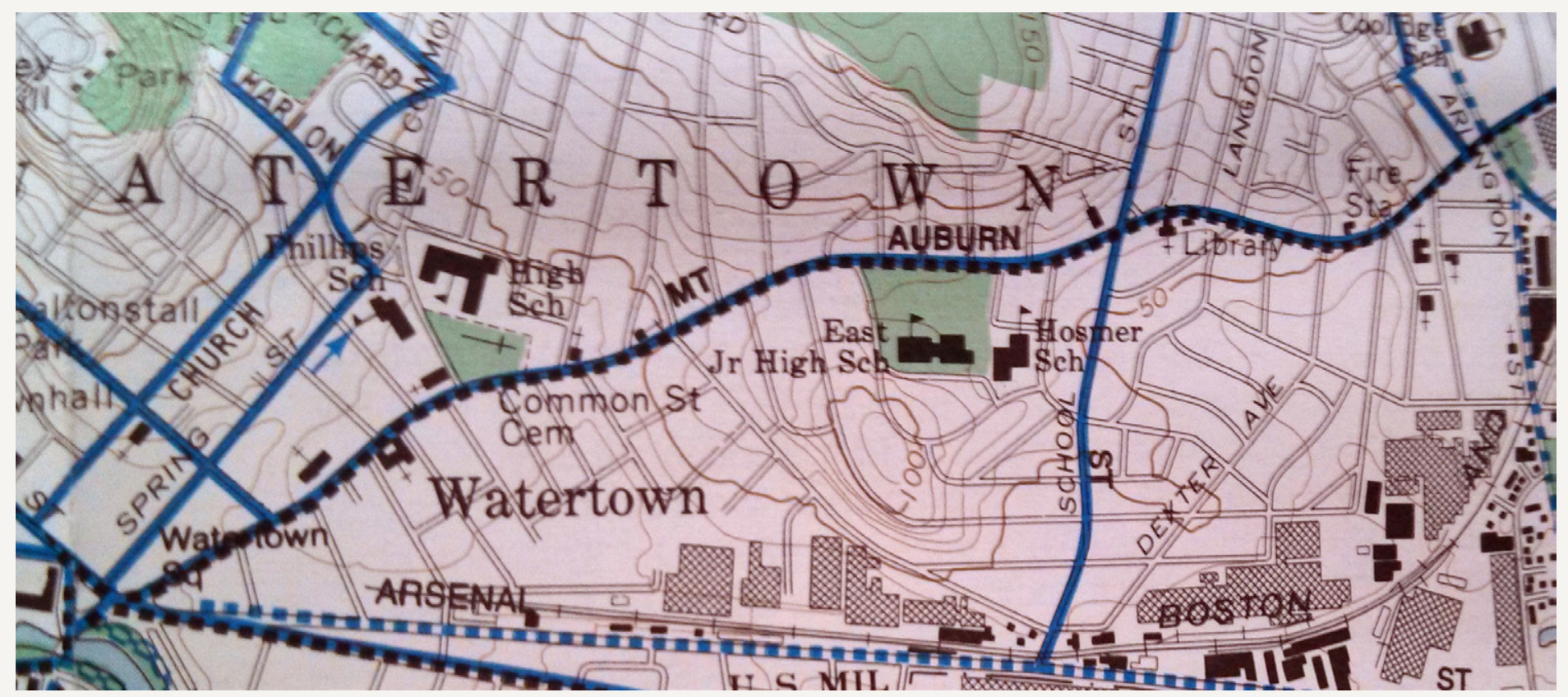

Figure 2. A map from Boston uses dense, fine contour lines to show topography. Blue lines show "bike routes" (BikeMaps Massachussetts 1994). 
The collective response of American policy makers to bikes over the last thirty years or so-when not simply ignoring them-has been to segregate them from cars and trucks by building specialized lanes and paths (see People for Bikes [2015] and John Forester's work generally). This is to be contrasted with a more European approach where bicyclists are (certainly not always but) more often integrated into urban traffic that, on average, consists of smaller vehicles operated with greater temperance. As of 2015, a great many bike lanes and paths have indeed been built in American cities (People for Bikes 2015), but even in the cities that have gone the furthest in this direction, these facilities only exist on a tiny fraction of all streets, and most bicycling almost certainly happens in a roadway shared with cars. The maps of this most recent bike boom have largely been made by city DOTs, and their segregative policy direction has naturally bled into their maps, and into the maps of other groups. Maps of this period emphasize specialized bicycle infrastructure-where it exists-and almost totally ignore most other streets (Figure 3). Such streets, if bike maps tell us anything at all about them, typically have their various interesting qualities reduced to a scale from good to bad. This is the same tactic used before by advocates for better pavement, though it's not clear any more who is to blame for the "bad" streets or what exactly might be demanded of them. This "good/ bad" distinction doesn't seem like a conscious political tactic any longer so much as an atavism, especially since it's often the DOTs themselves both making the maps and responsible for the roads.

The construction of segregated facilities is probably the most widely accepted goal among American cyclists

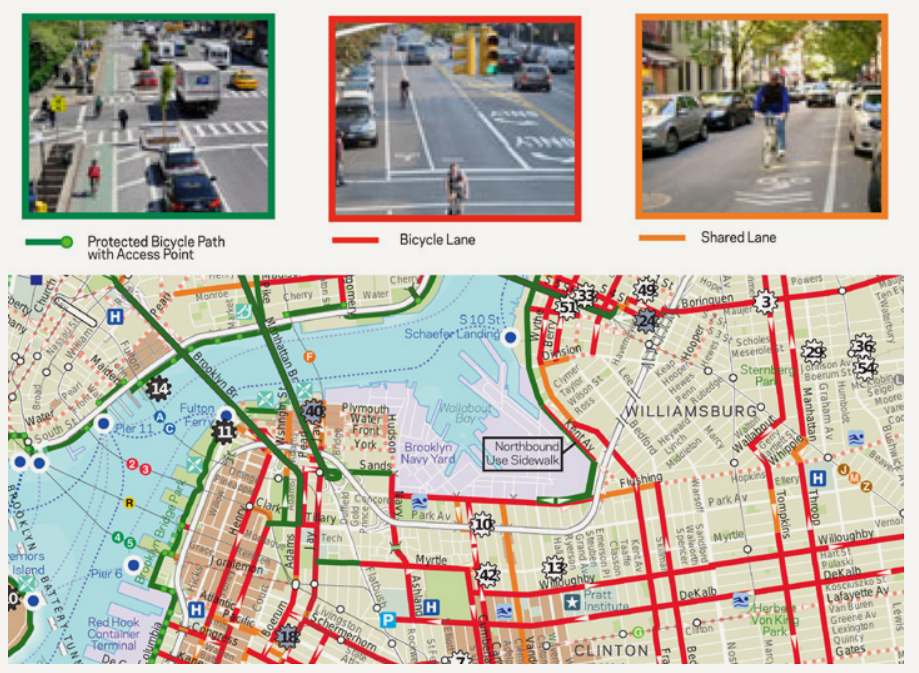

Figure 3. New York City has enough bicycle infrastructure to populate a map with objective content (City of New York 2012).

(People for Bikes 2015), but most cities don't yet have the political will to develop extensive lanes, as demonstrated by the fact that they haven't. Instead, such DOTs are often, among other things, making maps as a concession to cyclists, and as a sincere effort to encourage people to ride bikes. If the goal of these DOTs really is to encourage cycling while not immediately developing much segregated infrastructure, then more effective cartography, cartography aimed at helping cyclists to navigate in the world as it currently is, may actually be a great way of doing that. Better bike maps are unlikely to be as politically contentious as re-purposing part of a roadway, and they are certainly less expensive. Despite this potential, relatively little has been done to develop alternative approaches to making useful maps for cyclists in cities.

\section{CURRENT PRACTICES: LANES IN THE VOID}

AN INFORMAL REVIEW of several dozen contemporary urban bike maps, mostly from the US, reveals two broad types of map content which we will term objective and subjective for a lack of better words. Cartographers are perfectly familiar with the fact that ontology is a slippery business and that classifying things is one of the biggest challenges in making a map. There are, however, certain things that are more slippery than others. For example, it is hard to dispute whether or not a street has a bike lane: there is either paint on the street or there isn't. It is hard to argue that a bike path is actually a normal road when the question is decided by the presence of bollards and signs that keep the cars out. These are examples of objective features. On the subjective side though, we see things on maps like "preferred routes," "comfortable streets," and "difficult locations." No amount of definition could make such things incontestable, and they're usually not even well defined on the maps in which they appear. Maps themselves vary greatly in the proportion of objective to subjective content, though most seem to contain at least some subjective content. The variation in this dimension seems, anecdotally, to be well accounted for by the amount of bike-specific infrastructure in a city; cities with less bike infrastructure tend to make relatively subjective 


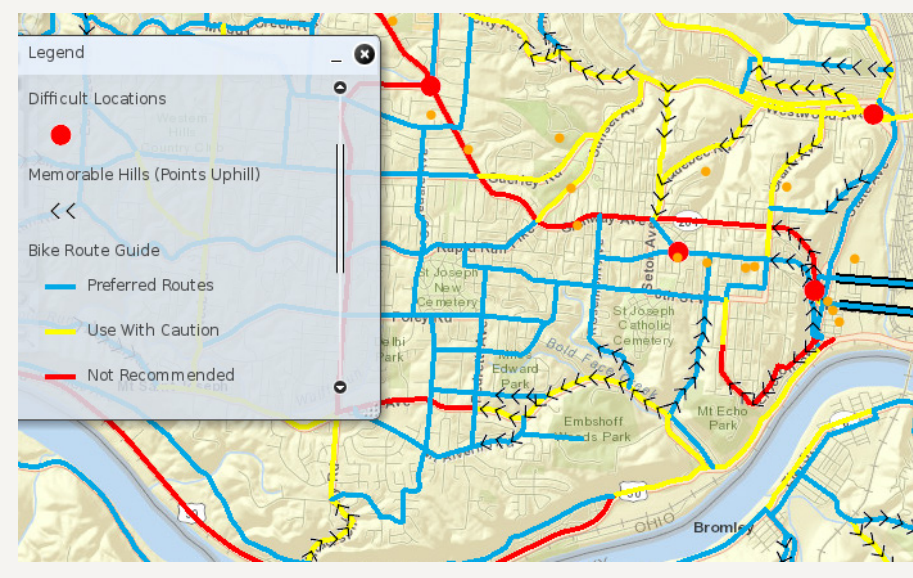

Figure 4. OKI's map of Cincinnati, if it focused on bike infrastructure alone, would be almost totally bare (OKI 2013).

maps. Objective content usually does a good enough job of describing itself (see Figure 3 for an example), so we will focus in the rest of this section on cataloging some types of subjective content. We will try to draw examples from a wide a range of cities, though we have limited our review to the United States.

Cincinnati's metropolitan planning organization (MPO) uses a three-tier scale to rate streets, from "preferred routes" to "use with caution" to "not recommended" (Figure 4). Washington DC's 2011 map (District Department of Transportation and goDCgo 2011) uses a scale from "good (or not evaluated)" to "fair" to "poor" and describes this content only as "street/road suitability for bikes." Google Maps, in their widely used bike map rendering, shows "recommended routes." A tremendous amount of searching for an explanation of this short phrase yielded only the following:

"For many cities we also provide information on streets that have been designated as good for cyclists, so we them [sic] into account in our algorithm. These roads are indicated with dashed green lines on our bicycling layer."(Leen 2010)

Los Angeles, in a 2011 map by their DOT, describes many streets on a scale from "comfortable street for biking" to "moderately comfortable" to "uncomfortable" (LADOT 2011). A map by the city of Boston (2013) shows a set of three "suitability rating levels": "beginner," "intermediate," and "advanced." This map is unusual in that it goes on to explain these categories with more than one or two vague words. "Beginner" for example is described as:
"Suitable for all types of bicyclists including newer cyclists, cyclists with limited on-road experience and/or children. These segments tend to be off-street paths or very low volume/speed roadways."

"Advanced" is described as:

"Suitable for experienced and traffic confident cyclists. These are often the most direct routes. Traffic volumes and/or speeds can be high. Intersections might be complex."

A 2013 map of Indianapolis gives the categories, once again with no further explanation: "most bikeable," "bikeable," and "least bikeable" (INDYCOG 2013). A map of Cleveland Heights in 2011 gives its readers roads "suitable for bicyclist[s] having basic skills," "intermediate skills," and "experienced bicyclists" (Cleveland Heights Bicycle Coalition 2011). The bike map of Columbus gives streets that are "good," "moderate," and "poor" and provides vague explanations (MORPC 2012). Countless other examples could be given.

Another subjective item common to many bike maps, is the "hill" (Cleveland Heights Bicycle Coalition 2011), the "memorable hill" (OKI 2013), the "steep incline" (City of Springboro 2014), the "climb" (Portland Bureau of Transportation 2011), and from Pittsburgh, the "steep hill" and the "very steep hill" (Bike PGH and Deeplocal 2011). These are all marked by arrows pointing in the uphill direction. No measure defining what qualifies as a hill was given for any of these maps. The closest we get to that comes from Seattle (Seattle Department of Transportation 2012), where the legend tells us that the frequency of the arrows "roughly indicates [the] steepness of [the] grade."

Another somewhat less common feature, included with safety in mind, is the "difficult location" in Cincinnati (OKI 2013), or "difficult intersection" in Los Angeles (LADOT 2011). In both cases, no further explanation is given.

This sampling does not exhaust the genre and it doesn't touch on bike maps in other countries, which also contain a great deal of subjective content if our personal experience is any guide. It should suffice though to demonstrate that subjective content is widespread in bike maps generally. Many other map genres make extensive use of subjective 
content, but not maps that are meant to aid in navigation. It's difficult to imagine a nautical chart showing water "too shallow for sailing;" instead, it would simply show the actual depth, because different boats have different drafts and sailors know perfectly well what these are. It's hard to imagine a transit map showing "preferred routes" without defining these explicitly: a map only of rail services for example, which would plainly exclude anything not on a steel rail. Imagine a state highway map that took the liberty of advising car-drivers to avoid whole stretches of highway- “interstates to avoid." Such suggestions, I hope, are clearly, perhaps comically, out of place and illustrate that subjective content has little place in a transport map aimed at a general audience. One might contend at this point that a bike map is not aimed at a general audience, but rather at cyclists specifically. But cyclists are not so uniform a group as might be supposed.

\section{DIVERSITY AMONG CYCLISTS}

THE ONLY THING that really lets us identify cyclists as such is the presence of a bicycle beneath them. Beyond that the similarities quickly break down. Some urban planners have acknowledged at least four main types of cyclists that guide their work (Dill and McNeil 2012):

- No Way No How cyclists: these are not active cyclists, but rather people who simply know how to ride a bike and maybe even own one.

- Interested But Concerned: These are good-weather riders, who might cruise around their subdivision or ride on a slightly busier street, but only if they can feel quite safe.

- Enthused and Confident: These riders may appreciate segregated infrastructure but are also comfortable operating with automotive traffic. This might be an average commuter or fast recreational rider.

- Strong and Fearless: Cycling is a part of these people's identity, and usually their primary means of transportation. Typically young, these cyclists ride fast and actively assert and maintain their position on the street among other travelers.

To these categories we should add the distinction between "vehicular cyclists" and those who use the street more passively. Vehicular cyclists take charge of their engagement with cars, claim a whole traffic lane while riding, and use body language to acknowledge and direct car drivers. This stance takes some confidence but is safer than doing otherwise when executed correctly (Forester 1976; 2001). Non-vehicular cyclists, probably the majority in most places, generally observe the often-repeated advice that they should ride defensively as though invisible to drivers.
These cyclists hug the curb, or ride in the gutter, and defer to cars in most situations.

Bicyclists further break down into recreational and utility riders. Recreational cyclists ride for fun and use some other mode for general transportation, while utility cyclists use a bicycle for many or all of their daily trips. Racers are a distinct sub-group of recreational riders, riding fast and often huddled together in large aerodynamic packs known as "pacelines."

Obviously, people can and do switch between and among multiple riding styles, not nearly all of which can be enumerated here, both over their lifetimes and from moment to moment. What does seem clear is that with this many ways of riding a bicycle, it can't possibly be easy to make a specific route suggestion of general utility to any cyclist anywhere. Racers on a training ride will often prefer a rural road with few stops that allows a rotating paceline to develop. Timid recreational riders may want only trails and many may be interested to know where they can park a car nearby. Utility cyclists will regularly need to access retail districts for the shopping and errands that direct most of their trips. New cyclists may wish to avoid hills, while the "Strong and Fearless" may seek them out for fun or exercise.

City DOTs in particular should be concerned with utility riders if they wish to supplant some car-trips, though it has been well-demonstrated that when more bicyclists of any sort use a street, the street becomes safer and more comfortable for other cyclists as cycling is socially normalized (Brüde and Larssen 1993). A map with recommendations aimed at any one type of cyclist presupposes that enough people exist in that category to constitute a reasonably large audience. But in cities where cycling is just 
beginning to (re)grow in popularity, in cities without extensive bicycle infrastructure, this supposition is probably unfounded. In these places, bike maps should attempt to speak to as broad and diverse an audience as possible.

\section{A BICYCLIST'S PERSPECTIVE}

Given All these different ways of riding a bike, what is unique to a cyclist's understanding of the world? What must be taken into consideration as any cyclist plans or considers making a trip? It will help to contrast bicyclists with other travelers.

- For lack of a better word, a fearful "friction" is created by cars as they pass cyclists from behind. This friction is experienced as the fear of being struck from behind and takes an emotional toll on most cyclists, though each has their own tolerance and comfort thresholds. It is felt to the degree of the difference between the speeds of cyclists and passing cars. Cyclists often seek to minimize this friction by speeding up themselves or by trying to slow down passing cars. Cars passing from ahead, as on a two way street, don't create friction, at least not to the same degree, because they can be seen and anticipated. The difference between the speed of the cyclist and the speed of the overtaking traffic is of prime concern.

- This same friction is also a function of the distance between cyclists and passing cars. Fast passing becomes much more tolerable when a lane or more of space is allowed between the passing and the passed. When little space is allowed, even a very slow pass may be intolerable.

- Cyclists feel hills much more than cars and more even than pedestrians since they climb them faster and with heavier equipment than the latter. Beyond the obvious physical stress, even very subtle grades can dramatically affect a cyclist's speed, which in turn effects passing friction dramatically. Many high-speed streets can feel very dangerous on the uphill ride and exhilarating on the downhill as a cyclist's speed approaches that of surrounding traffic and friction is reduced or totally eliminated.

- Totally car-free paths of various sorts exist as a distinct type. These may best be subdivided, as in the time before cars, by their paving type: gravel, asphalt, etc.

- Bike lanes define a distinct type of street that can provide a mental break from the active avoidance or management of cars, but which sometimes does little to minimize the friction caused by fast, close passing. Indeed, bike lanes can implicitly condone fast, close passing; a painted line rather than social controls comes to define the extent of a driver's obligation.

- Cyclists are uniquely able to engage in mode-switching: actively alternating between acting as vehicle, pedestrian and transit passenger as suits the needs of the situation. This, for example, makes short one-way streets only a very minor obstacle; a cyclist will almost always mount the sidewalk as a pedestrian rather than circle the block as a car would need to. A cyclist can also take a bus up a steep hill or use a stair as a shortcut.

- Cyclists feel the need to stop and accelerate as not only a time burden, but as a physical stress. This accentuates the relative importance of stop-lights and stop-signs. Excessive stopping and starting can lead to fatigue and diminished speed.

- Cyclists, like runners, are engaged in strenuous physical activity. While seated car-drivers can go hours without eating or drinking, cyclists must usually carry a water bottle and/or stop often for refreshment, particularly on long rides. This need emphasizes the relative importance of drinking fountains, restrooms, and places that allow cyclists to recharge and clean themselves up before arriving at a destination (see Dickinson [2012]).

How can these factors be measured and combined to form a useful map that empowers cyclists to make informed decisions for themselves? 
As WE've SAID, not a lot of work has been done on the problem of bike maps, at least as we've defined it, though there is some research worth mentioning here. In 2012, Evan Dickinson developed a bicycle trip planner for cyclists that emphasized experiences, particularly the enjoyable experiences, of riding a bike (Dickinson 2012). Among other things, it highlighted such things as public art, street trees, and human-scaled buildings by way of pictures, comments, and illustrations. The interactive nature of Dickinson's project, and the fact that it only focused on one route at a time let it do a lot that a static map could not, but it also means that most of the graphic techniques that he developed are not really applicable to a static map showing more than one route.

Other researchers, and some departments of transportation, have developed what they call a "Bicycle Level of Service" (see Landis et al. [1997] or FHA [1998]). These are basically regression models that are trained on a sample of cyclists and a sample of streets. The cyclists report how "comfortable" they would feel riding on a street (perhaps after seeing a video of the street), and the model takes some parameters for each sample street and gives coefficients that can be used to systematically rate other streets for which similar data is available. The models have produced very high $\mathrm{r}^{2}$ values, meaning that they seem able to predict the self-reported comfort of the study participants pretty well. Such ratings could easily be used to develop bike maps, though we have never seen any using this or a similar measure. In any case though, the result would still be a one-dimensional good-to-bad scale with little or no explanation as to how the rating for any given street was arrived at. The bicycle level of service is probably very useful for applications like trip routing and civic administration but it doesn't seem clear that it would be useful for a general purpose bike map.

\section{THE CINCINNATI BIKE MAP}

IN THE AUTUMN OF 20I4, this paper's first author, Nate Wessel, created the Cincinnati Bike Map with the help and encouragement of his academic advisor, this paper's second author, Michael Widener, at the University of Cincinnati. The goal of the project was foremost to improve on a history of unsatisfying bike maps in Cincinnati and elsewhere, seeing if the principles spelled out above could inform a legible and informative map useful for a diverse audience of cyclists. The map was also to serve the usual goal of a bike map, which is presumably something like helping people to ride bikes. The map's development and printing was funded by a grant from the Haile US Bank Foundation and by several other local sponsors. This led to a somewhat unusual design situation: because the money was given unconditionally by the Foundation and sponsors before the design was completed, and because no client needed to sign off on the design, we were unusually free to break with norms and expectations associated with printed urban bike maps up to now.

\section{OVERVIEW}

The map was designed for print, and measures 24 inches wide by 31 inches tall at a scale of 1:28,000. One full side is the main map showing the central and eastern neighborhoods (Figure 5A). The reverse side is half covered by the map of the western neighborhoods, and half by a series of three insets at a smaller scale (Figure 5B). Two of the insets reproduce the area covered by the main map at $1: 84,000$ and serve as indices for certain features that we wanted to include prominently, but which didn't necessarily need to stand out on the main map itself. The first such inset (top left of figure 5B) shows elevation, water fountains, and grocery stores. The second inset shows transit lines with frequent service running uphill. The third inset depicts regional bike-only trails at a scale of 1:400,000. Nine thousand copies of the map were printed and distributed free-of-charge throughout the Cincinnati region. For those interested in seeing the map in full, an online version is available at www.cincymap.org/cbm.

All vector data for the map came from OpenStreetMap (OSM). Originally the data were somewhat inadequate for our purposes and had to be supplemented with local knowledge and on-the-ground surveys. These additions were contributed back into the OSM database using a data model already well-established by the OSM community. Elevation data came from the US Geological Survey. 


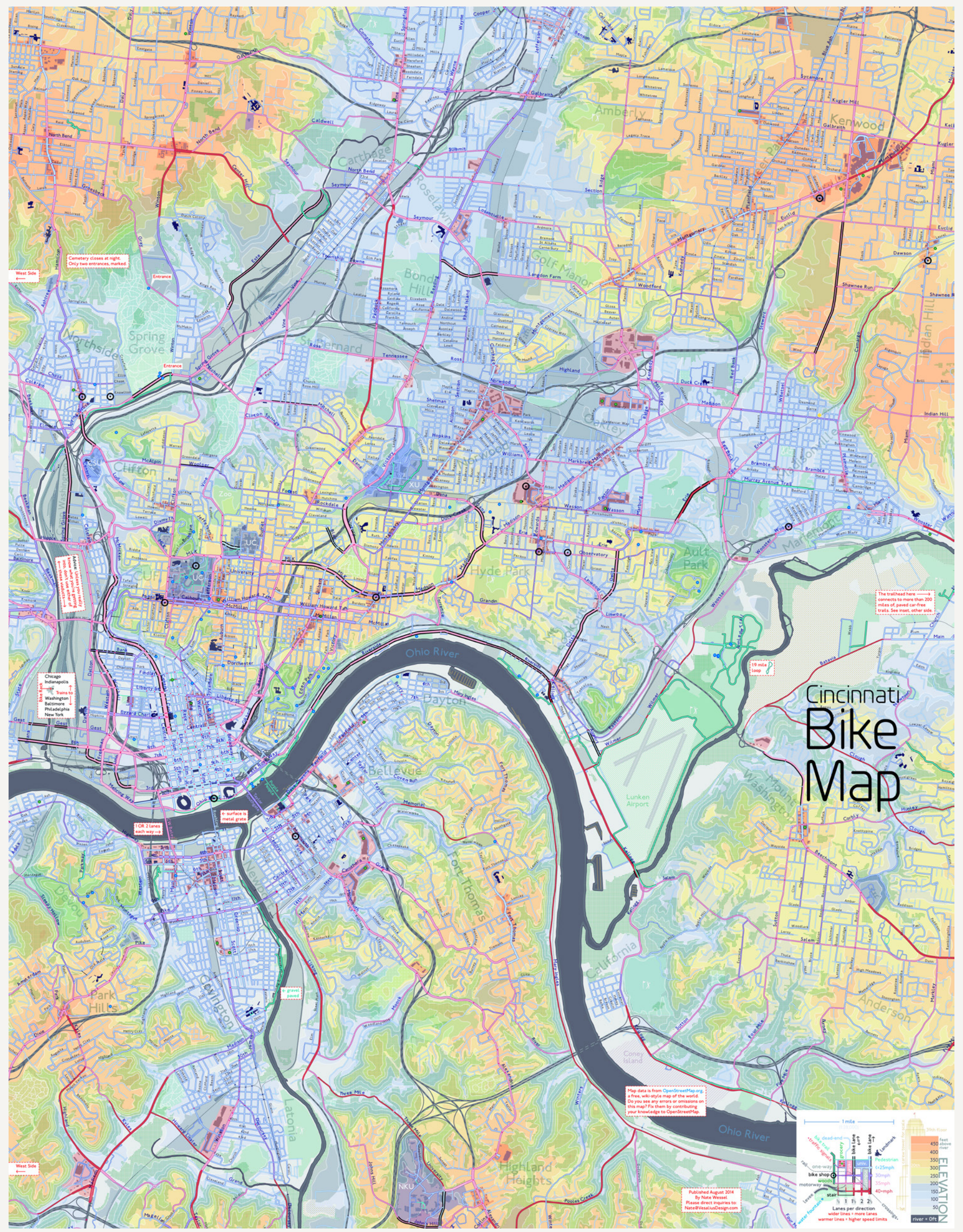

Figure 5A. East/central side of the Cincinnati Bike Map, originally 24" by $37^{\prime \prime}$ 


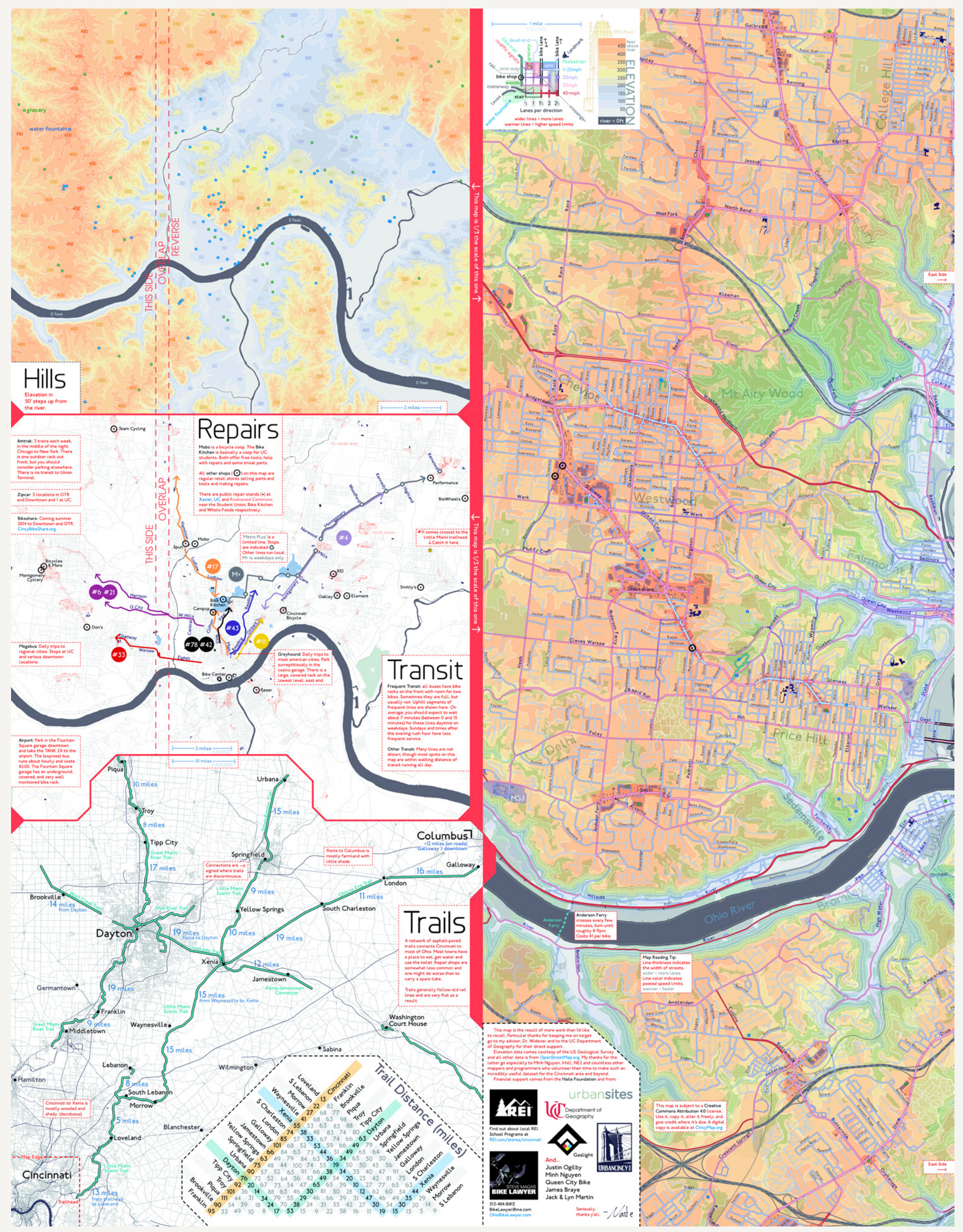

Figure 5B. Reverse side of the map showing west side and insets. 


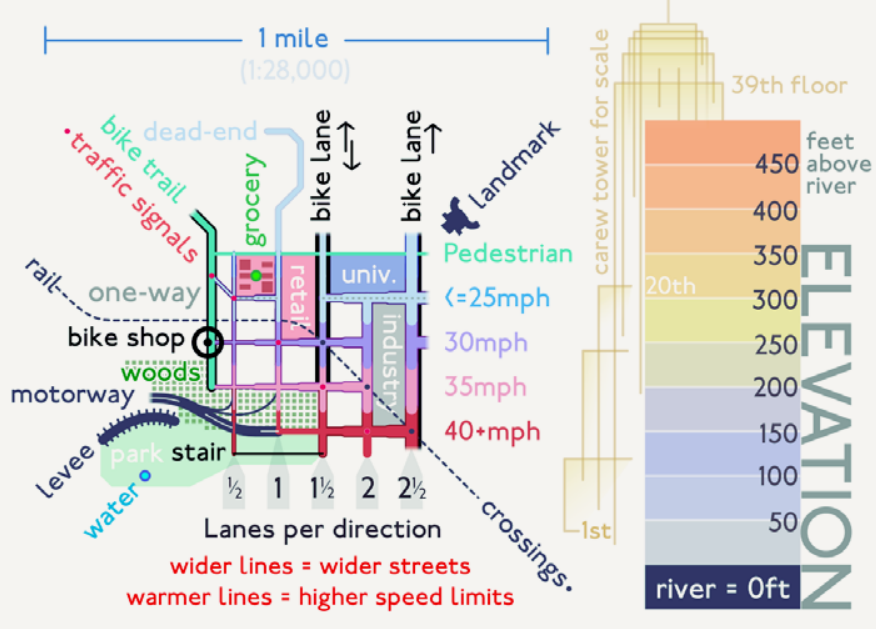

Figure 6. The legend of the Cincinnati Bike Map.

The legend (Figure 6) will help to guide the reader through the sections that follow where we will discuss in detail the various contents of the map.

\section{STREETS AND PATHS}

The presentation of streets should tell the cyclist about the nature of potential "friction" as we've termed it: the speed and proximity of cars passing from behind. Since the presence of cars is the initial concern, car-free paths and bike lanes should appear distinct from streets and paths that allow cars. Bike lanes were highlighted with bold black lines parallel to the street (Figure 7). Trails were shown with a vivid green and a high-contrast black border. On streets where some car-traffic is assumed to be present, color and line width were used to indicate the speed and proximity of cars, respectively. Speed, indicated by the color of lines, ranges from blue for the slowest ( $<=25 \mathrm{miles} /$ hour) to red for the fastest $(>=40 \mathrm{miles} / \mathrm{hour}$ ). We used the official, posted speed limit as the measure of speed; other, perhaps more empirical measures of traffic

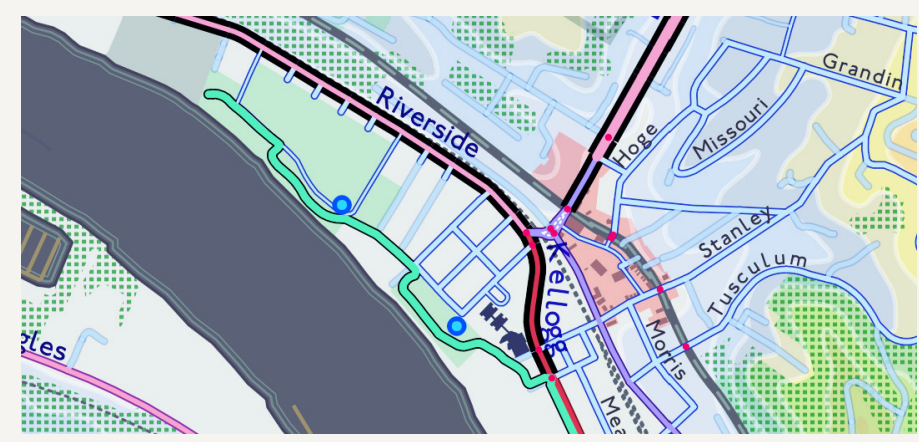

Figure 7. A bike path (green) along the river meets a street with a bike lane (dark border). speed might have served better, but were unavailable. The possible distance between the cyclist and the passing car was indicated by the width of the lines. There are several measures one could use for this as well, but we went with the number of full lanes per direction of travel. A twolane one-way street therefore is rendered twice as wide as a two-lane two-way street. The presumption implicit in this approach is that the width of the lane itself is unimportant because the cyclist is occupying a full lane. This may not actually be the best assumption in some situations, as we will discuss later.

The map also shows the possible connections between paths: both where they connect, and where they do not, since this is often different for bikes and for cars. For example, some long suburban streets may connect to each other by a small foot path. Or a whole branch of streets may only connect to a limited access highway at one end; such streets would be dead ends as far as any cyclist is concerned. We wanted to emphasize streets and paths which do let bikes through and deemphasize streets and paths which are effectively dead-ends. Fortunately, since data from OSM are implicitly topological, this was fairly easy to do. We used OSM2pgSQL to create a graph of streets and paths which are traversable by bicycles or pedestrians. Beside all ordinary streets, we included public stairs, pedestrian streets, bicycle-paths, and open-access service roads like alleys and some cemetery paths. We did not include highways and limited access trunk roads. We then used a PHP/SQL implementation of Tarjan's algorithm to decompose the complete graph into a set of distinct biconnected subgraphs. The largest of these subgraphs was what we might call the main street network, and the rest were connected to that by at most one edge. In simpler

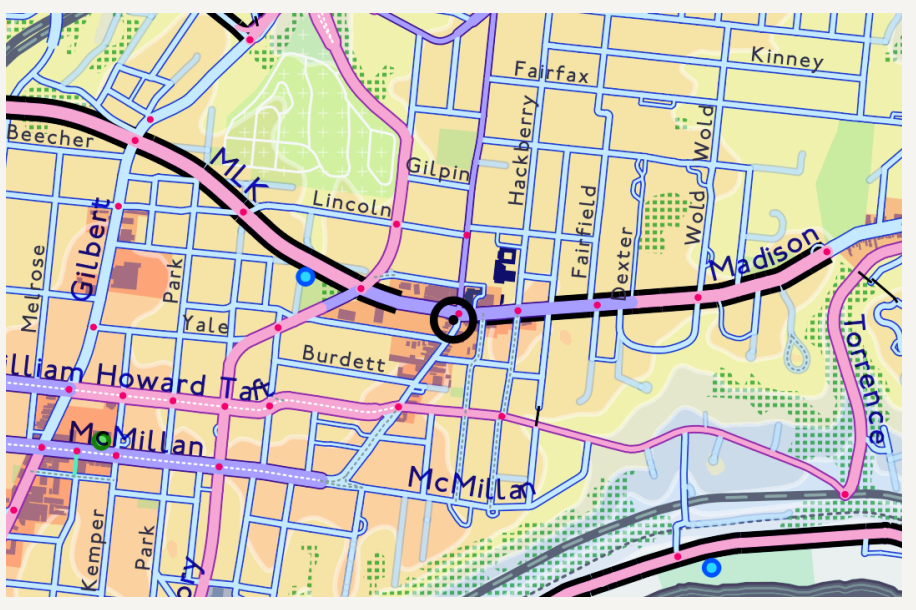

Figure 8. A variety of streets. 


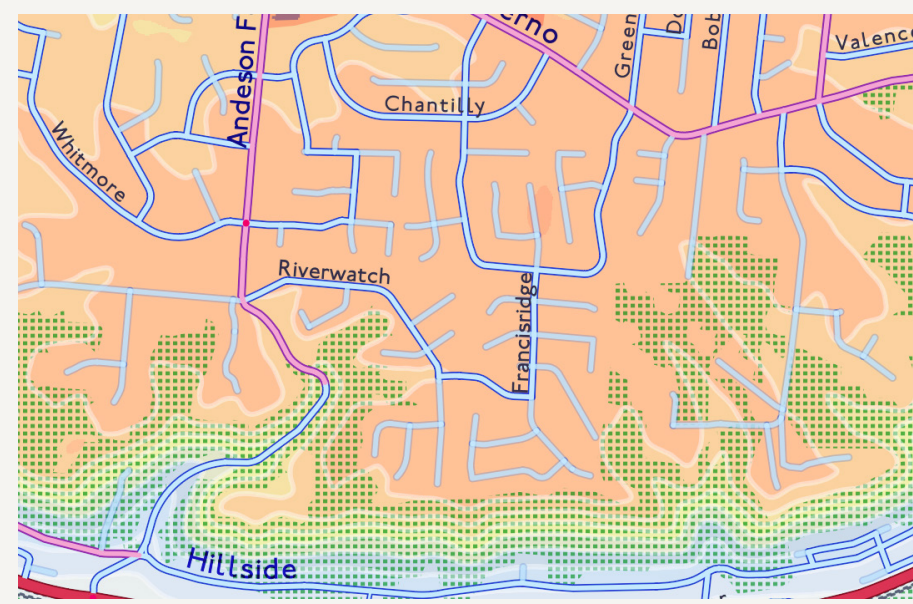

Figure 9. A suburban area showing the relative deemphasis of dead-ending street segments. The internal color of the line (showing speed) remains the same, but the contrasting border on the line is diminished, yielding a low value-contrast between the street and the elevation background.

terms, the algorithm answered the question of where "no exit" signs would be located if the world revolved around cyclists, and allowed us to select the streets that would be behind such signs. Dead-ending public streets thus identified were retained in the map but deemphasized by making the lines' darker border color mostly transparent (Figure 9). Dead-ending minor paths such as service roads and stairs were removed from the map completely.

The visual effect of deemphasizing the dead-ends was tremendous. The resulting emphasis on connecting streets helped to clarify many relationships which could otherwise have been ambiguous at this scale. This was a particularly important consideration in hilly Cincinnati, though a city with a stronger grid would tend to have fewer ambiguous connections and less distinction between the connections possible by car or foot. In our case, roughly $1 / 3$ rd of all paths (measured by length) on the map, which otherwise would have been rendered normally, were identified as dead-ends for bicyclists and rendered accordingly. Surprisingly, most readers didn't seem to notice initially that the dead-ends had been de-emphasized, though the visual difference was truly huge. One interpretation might be that this is because such streets play mostly a distracting role in wayfinding anyway, though other interpretations are certainly possible.

\section{HILLS}

A digital elevation model was obtained from the USGS, and zeroed to the normal level of the Ohio River, which is the lowest point on the map. Elevations were then divided into 50-foot (15.2 meter) steps up from the level of the river. By dividing the elevation into steps rather than using a smooth gradient or some direct measure of slope, we intended to help readers understand actual elevation changes rather than just assess relative steepness. Even without identifying particular elevations, a reader could easily count the steps between two points on the map and multiply by the 50 -foot interval between contours. Thus, five steps would equal a roughly 250 foot elevation change (Figure 10A).

Contour lines were avoided because of the potential for them to get muddled with the lines of streets; instead, we used a solid background with stepped colors. For these we chose some fairly unusual colors for a transport map (Figure 10B). In part, these colors were meant to imply nothing about landuse, but more importantly, they made the map look unusual. Once the color of one major map feature goes against a reader's norms or expectations, they may be more likely question their other assumptions and to look for a legend (Hoarau 2011). Particularly, we were concerned about the way street color (speed limit) and width (number of lanes) might be interpreted by a casual reader, since these are unusual elements for a normal map, but are critically important to understanding this one.

The map also includes a separate inset devoted to elevation (Figure 10B), since it can be difficult to read through the dense street network in places. Only one other map that we reviewed used some actual measure of elevation to depict hills (Figure 2). Instead, most bike maps seemed

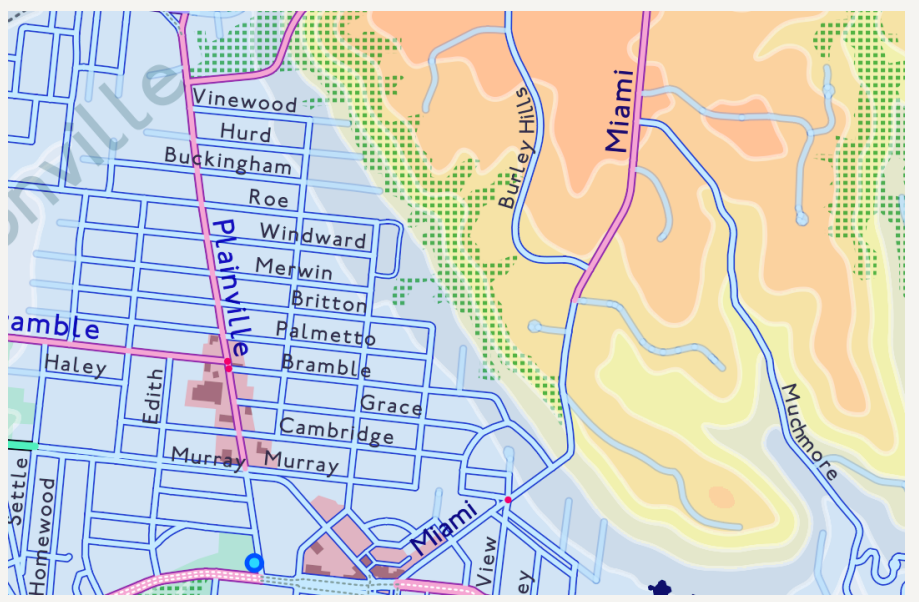

Figure 10A. Cyclists may estimate the length of a climb by counting the number of $50^{\prime}$ contour lines they will cross on the way up. 


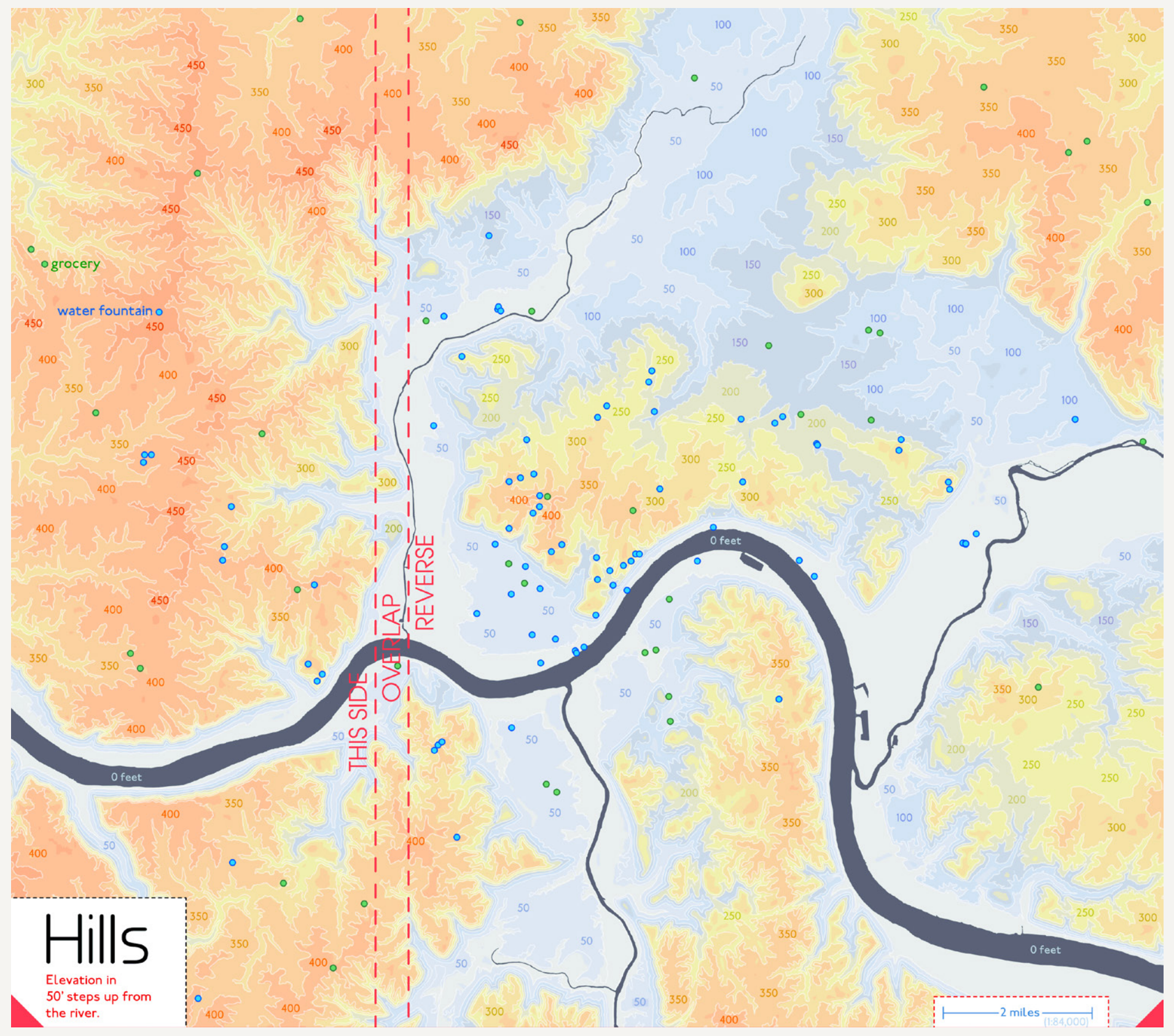

Figure 10B. Elevation inset. Certain point features that could get lost among the streets of the main map were also included here as an index because of their minimal interference with the elevation layer.

to use a subjective measure of steepness and depict it with arrow markers facing uphill and placed over the streets.

\section{INTERSECTIONS}

Some subtle information about the intersections of various paths was included. Traffic signals are indicated by a tiny red dot at intersections and railroad crossings by a grey one (Figure 11). Both are intended to be small enough to be noticeable only on a very close reading so as not to confuse readers needlessly.

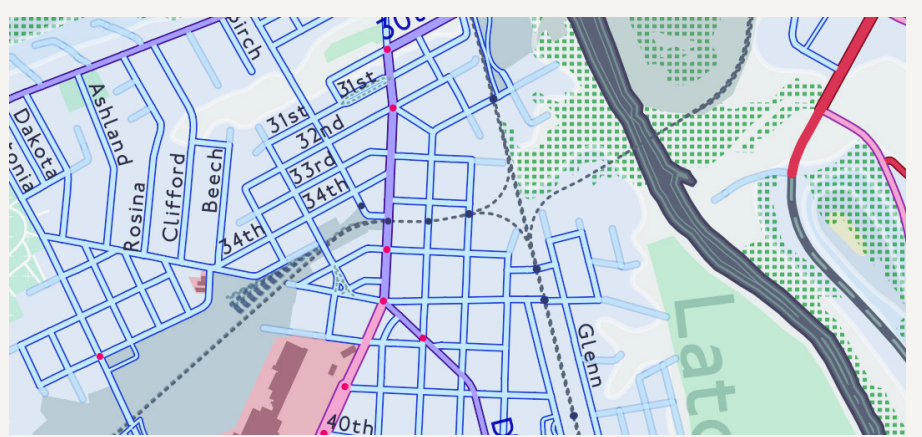

Figure 11. Section showing traffic signals (red dots) and at-grade railroad crossings (grey dots). 
The traffic signals may be read to indicate at least two things: first, the amount of traffic may be inferred to be higher in places where signalization has become necessary. Anecdotally, this is usually true for this map. Second, these are places where the cyclist may need to stop and start again. The railroad crossings are included to draw attention to what may be dangerous intersections between rails and roads. As with highways and trunk roads, rails are rendered below the streets and paths which cyclists can actually travel on. At-grade railroad crossings were indicated with a grey dot over the street line which serves to visually continue the rail line over the street. Rails, particularly when they cross a street at an angle or in wet weather, threaten to catch a bicycle's front tire and cause a wreck. To avoid this, cyclists will often slow down and swerve to hit the tracks perpendicularly. They need space to make this maneuver and may simply want to avoid such crossings if possible. The demarcation of crossings also makes clear where crossings are not, since many rail lines also cross above or below the roadway. One problem with this method is that it may confuse people looking for an actual bridge or a tunnel since it doesn't distinguish between the two but renders them both beneath the street.

On maps at a slightly larger scale than this, stop signs might well begin to be symbolized. Residential areas which don't make exclusive use of all-way stops will often have one or a few dominant streets which get priority at intersections. To represent this on a map, the same sort of tiny dot or perhaps a short perpendicular line could subtly disrupt street lines at the location of stops, thereby increasing the visual continuity of lines which do have priority at those intersections. Many such streets are otherwise indistinguishable here, though cyclists may be interested to find them.

\section{LAND USE}

Many streets that have a constant speed limit and width can vary through their length in both traffic volume and actual traffic speed. Some indication of land use may let the reader speculate meaningfully about the often desired, though missing, traffic and actual-speed data, as well as other aesthetic qualities they may be interested in (Dickinson 2012, 21). Identified land uses in this map include: retail areas, college campuses, industrial areas and woods.
Retail areas (Figure 12A) generally tend to be busier, often with many turning cars and more traffic than elsewhere. They are often destinations or landmarks in and of themselves, particularly in Cincinnati, which has many distinct neighborhood business districts. To further indicate the nature of retail areas, building footprints within them are included to subtly differentiate pedestrian-oriented retail (small, close buildings) from auto-oriented shopping centers. College campuses (Figure 12B) tend to have more pedestrians than other areas and car drivers might be expected to drive more cautiously. Industrial areas (Figure 12C) often have wider, more generous lanes to allow for turning truck traffic, though some people will be uncomfortable around larger vehicles.

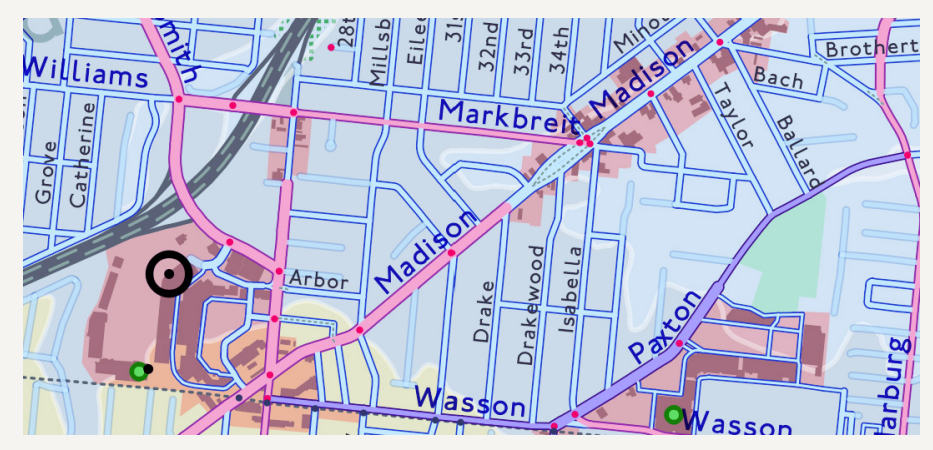

Figure 12A. Retail areas (red).

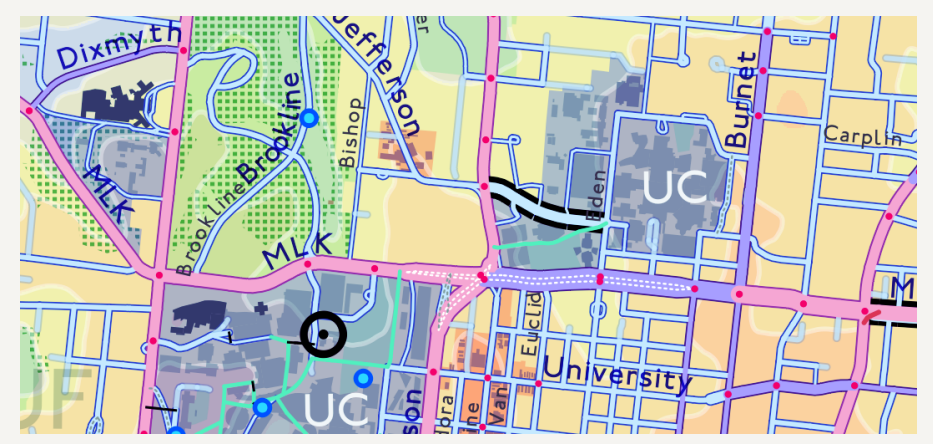

Figure 12B. University (blue).

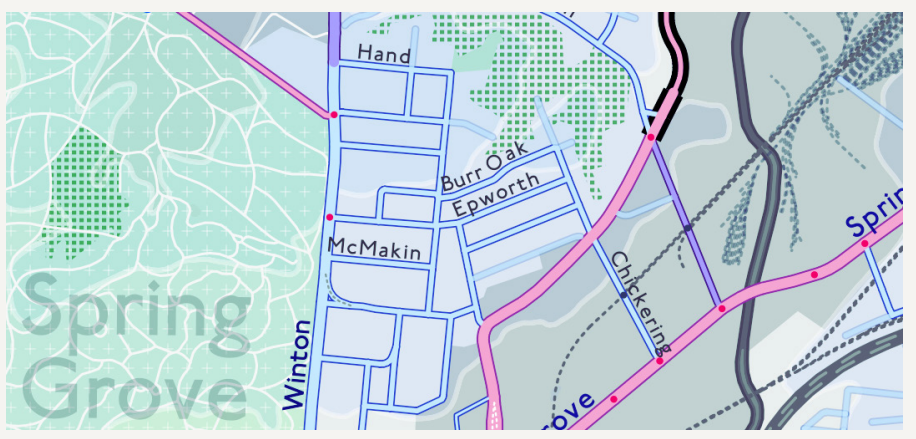

Figure 12C. Industrial (grey) and cemetery (light green). 


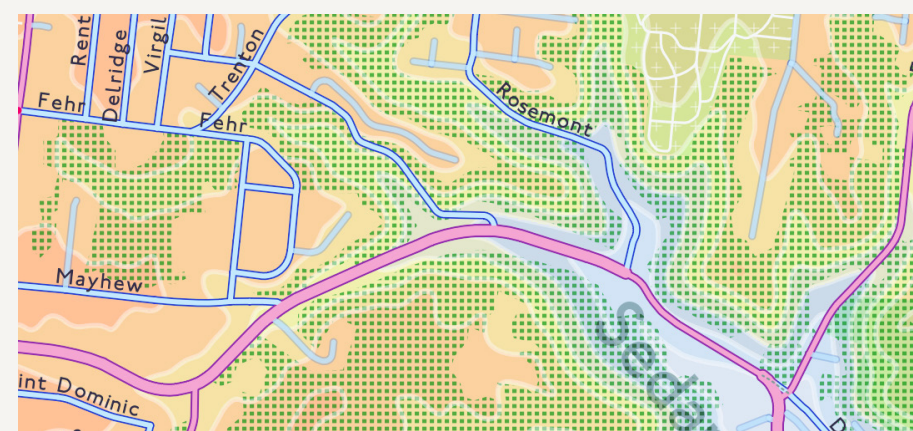

Figure 12D. Woodland (green pattern).

It is important to note that these interpretations are not provided as rules or even suggestions, and are certainly not provided on the map itself. These are our own subjective judgments which serve to justify the inclusion of various land uses. The reader should be free to draw their own conclusions based on their preferences and experiences riding in such areas. As elsewhere, we hoped to avoid including our own opinions, our own cynicism or optimism, where it might not be shared by the reader.

Wooded areas (Figure 12D) are included in part because they help to explain what are otherwise large, empty spaces, and in part because trees next to a hilly winding road often constrain a driver's line of sight as they come up behind a climbing cyclist. Only one other map we reviewed, Portland's (Portland Bureau of Transportation 2011; Figure 12E), addressed line-of-sight concerns. It did so with a noisy red border applied to the affected streets. Our own approach may allude to such concerns more naturally and relieve the reader of the need to recall a line symbol with a fairly limited application.

\section{DANGEROUS PLACES}

Several maps we reviewed highlighted certain intersections or other places which their creators deemed "dangerous" or "difficult." While such information may be interesting to many people, we think that land use combined with street width and speed limits will probably be just as good an indicator of "difficulty," and will certainly provide the reader with more information in most cases than a binary dangerous/not-dangerous classification. Still, if a cartographer wanted to include such information, they might do well to expound some actual criteria defining a dangerous intersection and then stick to it. Police records could be a good guide: perhaps something like clusters of 3 or more bike-related traffic reports in a one-year period could

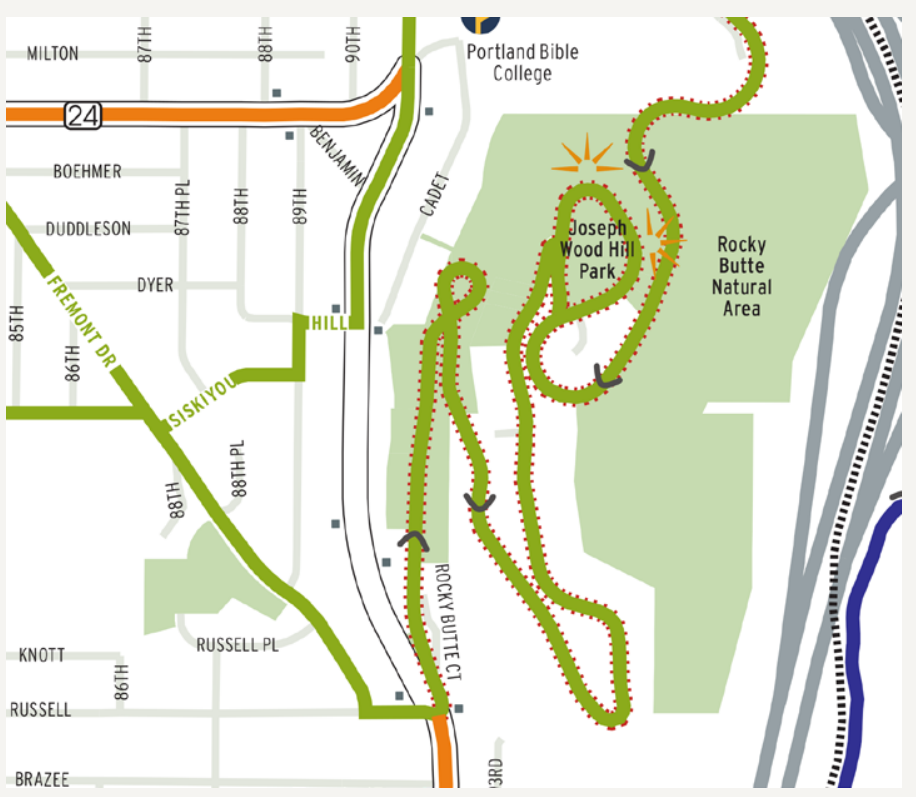

Figure 12E. An example of Portland's use of line symbols to show line-of-sight issues, which are almost certainly caused by woods.

indicate such places objectively. However, such a method would also introduce other problems, since bike accidents are notoriously under-reported (de Geus et al. 2012).

\section{TRANSIT}

Bikes can be taken on buses in Cincinnati, and cyclists often use public transit to get up some of the larger hills. One of the insets of the map therefore shows transit lines, but only those which both run up hill and which are generally frequent enough not to require reference to a schedule. This inset also serves as an index for the locations of bike shops with the idea that transit will be particularly useful at times when bicycle repairs are needed. The transit inset is one part of the map where we broke with our goal of explicitly defining our classifications. There is no indication of how we defined "uphill" or "frequent," and a visitor from a place like New York City or Colorado may perhaps misinterpret the intended meaning of these words.

\section{OTHER ELEMENTS}

Some other elements common to bike maps are important, but do not illustrate a uniquely objective approach. Amenities like bike shops, water fountains, and grocery stores are included in this map as well as most other bike maps we reviewed. Landmarks of one sort or another are also important, and landmark buildings, subjectively defined, were also included in this map. 
Nine thousand copies of the map were produced and distributed, and have been in circulation for several months at the time of this writing. The map has generated a great deal of feedback from all sorts of cyclists, including bike shop owners, professional advocates, transportation planners, young people, old people, and many others. This paper's first author has also made extensive personal use of the map in his daily travels and has some first hand experience with its strengths and failings. We have not conducted any formal surveys or user testing, though these would be interesting avenues for further research. The discussion that follows should be considered summary and anecdotal.

To start with the map's failings, we found that many people, despite our attempt to make the map look unusual by its overall color, jumped right into things without referring to the legend. These people tried to guess what the colors of the streets meant from their context, which didn't work very well at all since people aren't used to looking at maps of speed limits. Some of these people interpreted the colors as though they belonged to the standard bikemap good-bad scale. This was particularly frustrating of course, but at least not dangerously misleading since they generally took blue to imply safety and red to mean danger. Others didn't understand how the bike lanes were symbolized. These problems could presumably be fixed by increased familiarity with this map, or with other maps in the same style. It could also be helped by a more prominent legend or better instructions to the reader.

One comment, which we heard from more than a few people once they had understood the legend, was that they didn't trust the speed limit data. That is, not that they didn't trust the accuracy of the map, but that they didn't trust drivers to obey the laws. Some people were quite cynical on this point, and we couldn't help but sympathize with them. They said that they would like to know things like the actual speed of traffic or the actual amount of traffic on a street. The later measure was not on this map in any sense, but both measures could easily be quantified and rendered if sufficient data were available. It seemed that once some cyclists understood that data like speed limits were available for the entire city, they started assuming that other, more fine-grained data were available too and asking for that as well. This could imply that our drive toward objectivity was going in the right direction, but that at least a few people wanted to go even further in that direction and explore the data at an even finer scale.

One last concern, raised during review, was that such a colorful map may present difficulties for the color-deficient viewer. This is a real, but not fatal, issue for the deuteranopic viewer in particular. We did consider color-deficient users at several points in the design process and reached what we think is an acceptable compromise. A great deal of information is encoded with color in this map, but much is also coded with value, texture, and various line properties like width. We could have reduced the map's use of the color channel, but only at the cost of eliminating some amount of information or by shifting some of it into a different visual channel at the possible cost of legibility for readers with normal vision.

Success in design is usually silent, and it may be enough to say that we haven't received any significant complaints about other features of the map. One silence however is particularly troubling: no one has mentioned the de-emphasis of the dead-ending street segments. This deemphasis introduced a fairly radical change from the basic geometry of most street maps of the city ( $30 \%$ of all streets were strongly de-emphasized), but no one seems to have noticed their relative absence or cared enough to mention it. This paper's first author found this emphasis on connecting streets to be some of the most useful information on the map when actually planning a route. Is it possible that this technique was simply intuitive and helpful? A formal approach to testing the utility of this particular method would be very interesting, both for bike maps and for other types of transport maps as well since each transport mode would have its own dead-ends.

\section{CONCLUSIONS}

THE PRIMARY STRENGTHS of a bike map in the style this paper has proposed, at least as we see them, are as follows.

First, the relatively objective quality of such a map means that readers are free to interpret things as they please without trying to read through the cartographer's eyes. Instead of things like "steep hills," which could be almost anything, our map lets readers see roughly, but in actual numbers, how the elevation changes over any given route they might take. Similarly, instead of "dangerous streets," 
we present speed limits and lane counts and leave the reader to decide where they are comfortable riding.

Second, a bike map should precisely describe its most important features. While it is certainly possible for our map to be wrong in places, it will generally be wrong in such a way that the error will be easy to fix with little debate. A street either has some number of lanes or some other number and that's not usually a matter of opinion. This should make updates to the map easy, painless and cheap.

Third, our map provides much more information than other bike maps. Because each street simultaneously displays a number of different qualities (speed limit, lane count, directionality, presence of bike lanes, surrounding land use, and connectedness), the number of distinct types of streets it can potentially describe is huge- on the order of several hundred. Other bike maps may show as many as eight or ten types of streets, and these are generally limited by the number of colored lines that the eye can distinguish. More information can and should be included in bike maps by making use of multiple visual channels simultaneously.
The main drawback to this overall approach, if our anecdotal evidence can reveal such things, is that people are simply unfamiliar with reading maps like this and therefore prone to making interpretive mistakes. Otherwise, some readers seemed to be telling us that the map didn't go far enough, didn't give them enough information, even though it gave them many times more information than any previous map of the same city.

There is still a place for subjective urban bike maps. Many cities around the world have huge contingents of cyclists and enough of these people will surely ride in some particular way that a map aimed just at them will find an appreciative home. One can easily imagine enjoying a Triathloner's Guide to Central Park or a Fixed-gear Map of Brooklyn (complete with WiFi access points and coffee shops). But such focused audiences are the exception rather than the rule in $21^{\text {st }}$ century America. If DOTs and advocacy group are serious about wanting to help all cyclists navigate their cities, they should make maps designed with a larger audience in mind.

\section{REFERENCES}

American Society of Civil Engineers. 2015. "2013

Report Card for America's Infrastructure.” Accessed November 2. http://www.infrastructurereportcard. org.

Bike PGH and Deeplocal. 2011. Pittsburgh Bike Map, Version 4.

BikeMaps Massachusetts (Rubel BikeMaps). 1994. Boston's Bike Map.

Brüde, U., and J. Larssen. 1993. "Models for predicting accidents at junctions where pedestrians and cyclists are involved. How well do they fit?" Accident Analysis and Prevention 25(5): 499-509. doi: 10.1016/0001-4575(93)90001-D.

Calvert Lith. And Eng. Co. 1896. Guide Map of the City of Detroit for Bicyclists Showing Pavements.

City of Boston. 2013. Bike Routes of Boston.

City of New York. 2012. 2012 NYC Cycling Map, 14th edition.
City of Springboro. 2014. Biking in the Boro Pocket Guide.

Cleveland Heights Bicycle Coalition. 2011. Cleveland Heights-University Heights Bicycle Map.

Dickinson, Evan A. 2012. "How Bicycle Maps and Trip Planners Can Represent Experience.” Master's thesis, Simon Fraser University.

Dill, J., and N. McNeil. 2012. Four Types of Cyclists? Testing a Typology to Better Understand Bicycling Behavior and Potential. Working paper, Portland State University/Oregon Transportation Research and Education Consortium. http://web.pdx.edu/ jdill/ Types_of_Cyclists_PSUWorkingPaper.pdf.

District Department of Transportation and goDCgo. 2011. Washington, DC Bicycle Map.

Federal Highway Administration (FHA). 1998. The Bicycle Compatibility Index: a Level of Service Concept, Implementation Manual. McLean, VA: US Department of Transportation. FHWA-RD-98-095. 
Forester, John. 1976. Effective Cycling. Cambridge, MA: MIT Press.

Forester, John. 2001. "The bicycle transportation controversy." Transportation Quarterly 55(2): 7-17.

de Geus, Bas, Grégory Vandenbulcke, Luc Int Panis, Isabelle Thomas, Bart Degraeuwec, Elke Cumps, Joris Aertsens, Rudi Torfs, Romain Meeusena. 2012. "A prospective cohort study on minor accidents involving commuter cyclists in Belgium." Accident Analysis E Prevention 45: 683-693. doi: 10.1016/j. aap.2011.09.045.

Hoarau, C. 2011. "Reaching a Compromise between Contextual Constraints and Cartographic Rules: Application to Sustainable Maps.” Cartography and Geographic Information Science 60: 79-88. doi: $10.1559 / 1523040638279$.

INDYCOG. 2013. Indy Ride Guide.

Longhurst, James. 2015. Bike Battles: A History of Sharing the American Road. Seattle: University of Washington Press.

LADOT. 2011. Los Angeles Bikeway Guide.
Landis, Bruce W., Venkat R. Vattikuti, and Michael T. Brannick. 1997. "Real-Time Human Perceptions: Toward a Bicycle Level of Service". Transportation Research Record 1578: 199-126. doi: 10.3141/1578-15.

Leen, J. 2010. "It's time to bike." Google Maps Blog. Accessed Nov 2, 2014. http://google-latlong.blogspot. com/2010/03/its-time-to-bike.html.

MORPC. 2012. Columbus Metro Bike Map.

Ohio-Kentucky-Indiana Regional Council of Governments (OKI). 2013. Cincinnati 2013 Bike Route Guide.

People for Bikes. 2015. "Statistics Library/Facilities Statistics.” Accessed November 2. http:// www.peopleforbikes.org/statistics/category/ facilities-statistics.

Portland Bureau of Transportation. 2011. Portland Bike/ Walk Map (set of five maps).

Seattle Department of Transportation. 2012. Seattle Bike Map.

Smith, Robert A. 1972. A Social History of the Bicycle: Its Early Life and Times in America. New York: American Heritage Press. 